\title{
El teatro: el primer amor de Vargas Llosa ${ }^{1}$
}

\section{Luis Peirano}

\author{
No quiero ya ser escritor \\ ni poeta ni gran doctor \\ ahora quiero ser actor. \\ (Mario Vargas Llosa)
}

Mario Vargas Llosa está cumpliendo sus deseos de niño. Sueños expresados en el quinto terceto de su poema "Locuras", el que escribiera cuando cursaba el segundo año de media en el Colegio La Salle. Lo ha hecho actuando en varios escenarios a lo largo de los últimos años y diciendo desde la escena La verdad de las mentiras, ya sea a través de algunas piezas maestras de la narrativa universal, encarnando el papel de Odiseo en su propia versión del poema homérico que narra las aventuras de Ulises en su camino de vuelta a Ítaca y, más recientemente, en Las mil noches y una noche, una propuesta original sobre el clásico universal que recoge las historias que contaba Scherezada al sultán Sahrigar para salvarse la vida. En cada caso, Vargas Llosa ha contado con la colaboración de profesionales de la escena, especialmente de las actrices Aitana Sánchez Gijón en España y México, y de Vanessa Saba en México y el Perú.

Pero el interés de Vargas Llosa por el teatro tiene larga data y va mucho más allá de sus incursiones en escena como actor. Hay pocos escritores, incluidos los dramaturgos profesionales, que hayan producido y estrenado sus textos dramáticos en escenarios de todo el mundo durante los últimos treinta años, y la relación de Vargas Llosa con el teatro es muy antigua en su historia personal. Así lo ha hecho saber desde hace algunos años y cada vez con mayor desenfado. 
En las primeras líneas del breve pero contundente prólogo que reúne sus primeras cinco obras de teatro, dice: "Si en la Lima de los años cincuenta, donde comencé a escribir, hubiera habido un movimiento teatral, es probable que, en vez de novelista, hubiera sido dramaturgo. Porque el teatro fue mi primer amor...." Prueba de su vocación adolescente había sido sin duda $L a$ huida del Inca, escrita nada menos que en el Colegio Militar Leoncio Prado y que se estrena poco tiempo después en Piura con gran movimiento de gente e instituciones. "Viajé con La huida del Inca bajo el brazo" recuerda el autor, para poner mayor énfasis en su interés por su ópera prima. El estreno de esa obra desconocida ha merecido relatos propios y ajenos, que dicen de las dificultades que tenía en el Perú (y tiene aún, a pesar de todo lo avanzado en este aspecto), y de quienes quieren enrumbar su interés vocacional por el teatro. Durante muchos años, sin embargo, no se le conoció ninguna otra actividad con el teatro, salvo la de entusiasta espectador. No estoy totalmente convencido de esto y creo que todavía es un tema por explorar en su biografía.

Lo cierto es que hoy ya no cabe duda alguna de la vigencia del primer amor de Vargas Llosa por el teatro. A propósito de sus primeros estrenos, Vargas Llosa había ya confesado, verbalmente y por escrito, el impacto que le causó ver en el Teatro Segura de Lima La muerte de un viajante de Arthur Miller montada por la compañía argentina de Francisco Petrone. La posibilidad de mezclar tiempos y espacios en un solo relato vital directo e inmediato debe de haber sido un importante estímulo para su creatividad narrativa, y sin duda una contribución a la marca de su estilo literario en su obra narrativa.

Fue también muy importante su amistad y admiración por Sebastián Salazar Bondy, que fue poeta, narrador y periodista, pero que estuvo muy involucrado en el teatro como autor, estrenando varias obras en los años sesenta. Salazar Bondy decía cada vez que podía que lo que realmente le hubiese interesado a Vargas Llosa era ser actor. Su vínculo afectivo con los grupos de teatro, especialmente con Histrión, teatro de arte, pero también con el Club de Teatro de Lima, fue muy estrecho. El apasionado enamoramiento de Bondy de la actriz argentina Inda Ledesma, a quien siguió con la compañía de teatro de Pedro López Lagar que había visitado Lima, le permitió empaparse del teatro de Buenos Aires y a su regreso a Lima fue un verdadero promotor de la actividad teatral. Éstas y otras señas marcaron buena parte de la biografía de Salazar Bondy, quien fuera amigo querido y admirado por Vargas Llosa. De hecho puede decirse que de alguna manera le ha seguido los pasos no solamente como dramaturgo, sino como amador cabal del teatro, sorprendente en los gestos y manifestaciones de apoyo a quien comparta este compromiso. 
No obstante, su aparición formal como autor de un texto puesto en escena fue con la versión de su novela corta o cuento largo, Los cachorros, que fue montada en el Teatro de la Universidad Católica con Alonso Alegría en 1970. La versión tuvo tanto éxito que el TNP repitió la experiencia en años posteriores, con un nuevo montaje, y el Teatro del Sol hizo su propia versión minimalista con los lamentablemente desaparecidos Pipo Ormeño y Beto Montalvo. Posteriormente se han hecho varios montajes.

Estos estrenos diversos de Los cachorros deben haber sido suficiente estímulo para que se animara a escribir ya directamente para la escena, porque a los pocos años convocó a gente de teatro, entre ellos a sus amigos del Teatro de la Universidad Católica (TUC). Luego se fundó el grupo ENSAYO para leer La señorita de Tacna. Se recuerda muy bien la emoción del autor al presentar a viva voz su primera obra y la buena impresión que causó, así como el desafío que planteaba. Quedó claro, sin embargo, que siendo una pieza que combinaba la fuerte presencia de un narrador (el personaje Belisario que nosotros llamábamos Belimario) y con exigencias mayores para la actriz que tomara el papel protagónico, no seríamos capaces de aceptar el reto de ponerla en escena. Para fortuna suya, lo asumió y estrenó con gran éxito en el Teatro Blanca Podestá de Buenos Aires el 27 de abril de 1981 Miguel Alfaro, protagonizada por Norma Aleandro, y giró por muchos escenarios hasta llegar a Lima donde se presentó en el Teatro Marsano.

Yo no sé si en ese entonces Vargas Llosa ya tenía alguna aspiración de subirse al escenario como actor, pero la pasión que ponía en su lectura nos hacía presumir que alguna inquietud de este tipo guardaba en el alma. Nuestra broma sobre el nombre del personaje Belimario daba cuenta de ello. “¿Crees tú que quiera actuar? No, hombre, ni hablar del asunto.” ¡Ni actuar, ni ser político! La historia nos daría respuestas contundentes al respecto. Volveremos sobre este tema.

No pasó mucho tiempo y Vargas Llosa nos convocó para leernos Kathie y el hipopótamo — según algunos colegas su mejor pieza de teatroque fue inmediatamente pedida por los mismos productores de La señorita de Tacna, y fue estrenada en el Festival del Teatro de las Naciones en Caracas, siempre con Norma Aleandro en el papel protagónico y con la dirección de Miguel Alfaro.

Debo reconocer que en cada caso discutimos con los amigos de ENSAYO nuestro interés por montar sus obras, pero no pudimos hacerlo hasta el 30 de enero de 1986 en el Teatro Canout de Lima, con el estreno mundial de La Chunga, muy pocos días antes de que sucediera lo mismo en Nueva 
York, el 7 de febrero del mismo año, con una versión al inglés por el INTAR THEATRE. En el montaje peruano de La Chunga, Vargas Llosa asistió a los ensayos con enorme interés - incluso "calentaba" cuerpo y voz con los actores y observaba con detenimiento y discreción los ensayos haciendo anotaciones y comentarios-, pero solamente al director una vez acabada la sesión. Su presencia y apoyo fue muy especial y decisivo para el conjunto del elenco. A los pocos años, estrenó en Londres El loco de los balcones y posteriormente, en el año 2003, lo hizo en Lima con la dirección de Alonso Alegría y con Enrique Victoria en el rol protagónico.

La quinta obra de teatro publicada primero en Lima pero también en el tomo de teatro dedicado a su obra reunida ya citado, es Ojos bonitos, cuadros feos, que fuera escrita originalmente para la radio y tuvo su estreno teatral en el teatro del Centro Cultural de la PUCP por el Grupo ENSAYO en 1997. Todas estas obras se han dado en escenarios diversos a lo largo de los últimos años.

Si tuviera que analizar el proceso seguido por Vargas Llosa en su dramaturgia de los textos mencionados, lo haría bajo la siguiente secuencia. Uno: un narrador convertido en personaje cuenta la historia de la protagonista y ordena la acción dramática. Dos: dos personajes se reúnen para acordar cómo contar historias (en palabras del autor se reúnen en sesiones de dos horas para mentir) y al hacerlo representan varias acciones. Tres: varios personajes cuentan su historia sobre un mismo acontecimiento, el mismo que involucra su relación con un personaje desaparecido. Cuatro: un personaje cuenta su historia pero lo hace enfrentando a quienes no lo quieren escuchar, no lo entienden o simplemente lo tratan como loco. Cinco: dos personajes entran a escena con propósitos tan distintos como bien definidos, aunque finalmente cuentan la historia de un tercero.

Más allá de interpretaciones subjetivas, a las que nuestro autor no les guarda temor alguno, contar una historia es para Vargas Llosa algo fundamental, aunque ha ido variando en hacerlo con procedimientos narrativos cada vez más propios de la dramaturgia. La narrativa literaria sigue siendo su arma principal para crear, eso es inobjetable, pero va cediendo paso a la presentación de situaciones concretas en las que el drama no requiere de explicaciones más allá de las que ofrece la acción, el quehacer concreto de los personajes, el diálogo entre ellos, tanto en los silencios como en las demás implicancias escénicas.

Como él mismo ha declarado al hablar de su narrativa en general, su preocupación no está centrada tanto en la técnica como en la vitalidad de 
la historia y, dentro de ella, en la subjetividad de cada personaje a menudo hecha explícita en soliloquios con un lenguaje que no le teme al candor ni a la muestra de vivencias de incuestionable intimidad.

Hay quienes han reprochado a su teatro el ser demasiado literario y narrativo. Si bien hay alguna razón para señalar el obvio acento en lo primero, no hay ninguna razón que tenga seriedad suficiente para objetar lo segundo. Basta revisar la historia del teatro y cuanto más la historia de la literatura dramática para constatar el valor narrativo presente en la teatralidad sin objeción alguna.

La sexta obra de Vargas Llosa se llama Al pie del Támesis y la estrenamos en el Centro Cultural Peruano Británico de Lima con mi dirección en el año 2008. Dos personajes se encuentran en un hotel en Londres para esclarecer qué pasó con otro personaje muy querido por ambos y que ha desaparecido de sus vidas hace muchos años. La acción los lleva a descubrir que dicho personaje es en realidad uno de ellos que se ha cambiado de sexo. El contar la historia de cada uno a partir de preguntarse por el tercero aparece aquí como un recurso técnico que dispara situaciones en la imaginación de ambos hasta el punto de hacernos olvidar el lugar exacto donde empezó el drama y permitirnos pensar que el punto de partida realista no fue sino un mero pretexto para ese encuentro que puede suceder, incluso, sólo en la imaginación. Cuando se ha agotado este juego escénico, el autor nos devuelve a la realidad con otro recurso que deja el final de su historia en el campo inagotable y maravilloso de la ambigüedad. No hay aquí nostalgia ni propuesta de interpretación explícita. El juego dramático nos lleva a confrontar vivencias complejas de la amistad y de la sexualidad sin pronunciamientos de moral o buenas costumbres.

La experiencia de los ensayos y de la propia temporada de funciones a teatro lleno nos permitió otra vez explorar en el universo de este autor limeño, local y a la vez cosmopolita, absolutamente universal. Al describir la experiencia, los miembros del equipo al que se integró completamente el autor, nos hemos sentido apoyados en el profundo sentido de verdad que guía a los personajes, pero a la vez rozando las distintas formas culturales, expresadas también en gestos y ademanes que les dan vida y que tienen que ver con una manera de ser y de sentir que no es solamente limeña pero que se nutre directamente de su experiencia más íntima.

Soy testigo privilegiado del interés, el gusto y el vínculo visceral y protagónico de Vargas Llosa con el teatro. El centro de su creación está en el arte de contar historias, en las que se producen situaciones muy complejas 
con frecuente uso de recursos que convocan a la representación. Buena parte de sus relatos y novelas han merecido también la atención de gente de teatro y de cine, para hacer adaptaciones. La ciudad y los perros y Pantaleón y las visitadoras tienen varias adaptaciones teatrales y cinematográficas, y en los últimos años Lima, Bogotá y Nueva York, han visto la versión hecha por Jorge Alí Triana de La fiesta del chivo.

Cuando en plena madurez Vargas Llosa vuelve a sus orígenes teatrales, lo hace obteniendo un resultado distinto y en ocasiones controvertido. Por encima de absurdos cuestionamientos a su eficiencia como dramaturgo, comparándola con la de novelista, sus propuestas teatrales tienen siempre la carga feliz de contar una historia relevante que ofrece elementos vitales para la vivencia teatral que el público recoge con interés y apasionamiento. Lo confirma un dato irrefutable: pocos dramaturgos pueden exhibir tantos títulos estrenados con éxito en tan poco tiempo.

La memoria y la manipulación creativa de los recuerdos, de los sueños, de las pulsiones de todo tipo que nos agobian y entretienen en la vida son parte sustancial de su trabajo creativo. El impulso de síntesis - de presente continuo - que exige el escenario, es el resultado de un oficio que el autor ha ido puliendo detenidamente, primero como espectador apasionado de teatro, luego como escritor y más recientemente como intérprete.

Son ampliamente conocidas y discutidas sus recientes apariciones como protagonista, como contador de historias, pero cada vez más claramente confrontando su papel de narrador con la de actor protagónico. Estoy convencido de que será muy difícil que se detenga en llevar adelante esta vocación por entrar cada vez más en el mundo cautivante y maravilloso del teatro. Prueba de ello son sus dos últimas propuestas escénicas, Odiseo y Penélope ${ }^{2}$ y Las mil noches y una noche, hechas con el propósito explícito de estar en la escena como protagonista. Quizá sea necesario explicar expresamente el uso de la palabra "actor" para referirnos a su trabajo en escena, porque Vargas Llosa no es, en sentido estricto, un actor sino alguien que ama sin perjuicios el teatro y se presta a ser actor. Para ello escribe unas versiones de grandes textos que permitan su presentación en escena y donde él pueda cumplir su tarea de narrador representándose en primer lugar a sí mismo y luego a quienes hubiese menester. Los maestros de actuación enseñan que lo primero que debe aprender quien pretenda ser actor, es saber quién es él mismo y a manejar su cuerpo, su voz y sus vivencias y pulsiones personales, para que luego pueda hacer otros personajes distintos de él mismo, aunque 
los haga luego sobre los talentos y limitaciones de la materia física y psíquica de la que dispone.

Vargas Llosa se ha entretenido explicando las motivaciones para las distintas maneras de regresar a su primer amor. Ha escrito así sobre las impresiones que le causó ver las experiencias escénicas de Alessandro Baricco y de cómo ellas le sirvieron de estímulo para leer, para decir, para contar desde la escena, historias que pueden interesar a un público, ciertamente más reducido que el de sus lectores, pero que se ofrece como complemento a su esfuerzo con una respuesta inmediata y completa, imposible de obtener con la literatura.

De igual manera ha escrito con pasión sobre Dickens y su vocación madura por el escenario. Al hacerlo, no solamente ha dado cuenta de la vitalidad de este hombre genial por difundir directamente su obra dándole cauce a su vocación por la escena, sino que se ha preocupado por buscar testimonios de la pasión de Dickens por el teatro para confirmar que su interés iba mucho más allá del mero afán de repetir en escena su producción literaria. Los testimonios dan fe de que Dickens hacía todo o casi todo lo que hace un actor-cabeza de compañía, cuidando cada detalle de su presentación bastante tiempo antes de la misma, no sólo para los ensayos, sino para la soledad que permite la concentración creativa necesaria para quien va a convertirse en esa especie de demiurgo que es necesariamente un actor protagonista. Por lo que he visto, Vargas Llosa ha hecho mucho más en su afán de convertirse en intérprete de sus personajes a través de una vía distinta a la del estímulo de sus predecesores literarios. No se vestirá de levita ni usará pupitre, no dispondrá de uvas ni de bastón, tampoco se hará responsable del cuidado de la acústica y la utilería - como en efecto parece que hacía Dickens-pero sí de garantizar que los textos que dan pie a una puesta en escena tengan la grandeza que amerite el esfuerzo de producir un espectáculo en el que, sin renunciar a ser quien es, pueda proponer la convención de ser no solamente el protagonista, como Odiseo o Sahrigar, sino la convocatoria de diversos personajes que contribuyan a dar vida a sus historias en el escenario. Para ello ha sabido escoger con quién hacerlo en España y en el Perú.

Permítanme compartir la mejor prueba que yo tengo del interés de Vargas Llosa por el teatro al contarles de mi imprudente, o tal vez mejor sería decir pretenciosa, propuesta de hacer una versión propia de Las mil noches y una noche. Como yo no puedo nunca ocultar mi envidia por la condición del actor y mi deseo de volver al escenario como tal, le dije también que a mí me gustaría hacer el papel de Sahrigar. Su respuesta a mi pedido fue afirmativa y 
generosa como siempre, pero con un añadido insospechado: "Podemos hacer Sahrigar un día tú y un día yo". No creo que nadie haya recibido una propuesta semejante. Pero sí me he permitido contar esta conversación privada porque me parece clave para entender el amor de Vargas Llosa por el teatro y ubicar su contribución a la escena contemporánea.

Entre quienes tenemos la responsabilidad de enseñar teatro en nuestra universidad hemos definido tres instancias de aprendizaje básico: 1) acción, 2) palabra y 3) personaje, que corresponden a los tres cursos primeros de actuación en el entendido de que, siendo los tres muy importantes, se hace necesario establecer puntos de concentración en cada etapa de formación. La preocupación por el personaje está destinada solamente a quienes quieran hacer del teatro, y mucho más de la actuación, su opción académica y profesional, no porque sea la más fácil o la más importante, sino porque es la que marca el derrotero del trabajo creativo del actor. Hay actores que serán siempre un personaje, por elección o por limitación. La historia del teatro nos muestra actores que hacían siempre, si no el mismo papel, el mismo tipo de papel. Sucedían en las compañías que reclutaban actores para hacer de galán, dama, joven, cómico joven o viejo, característico, etc. Con frecuencia el actor no ocultaba su identidad; si había adquirido cierto prestigio, el público lo aplaudía al salir a escena, costumbre detestable para un actor que quisiera hacer un personaje distinto cada vez. Sir Lawrence Olivier contaba que su preocupación principal al salir a escena era que el público no pudiese reconocerlo, aunque tarde o temprano fuera imposible que no supiese que era él en el papel de Otelo o de Ricardo III. El teatro contemporáneo ha exigido con énfasis diversos la transformación como parte vital del trabajo del actor. Sin embargo, esto que sigue siendo parte del naturalismo psicológico en la técnica de actuación no tiene por qué ser un requisito imprescindible en la actuación, llegando incluso a plantearse la necesidad de dejar muy en claro para algunas propuestas teatrales la identidad del actor. No me refiero a la propuesta de Brecht, que es sin duda la más importante como la de mayor pretensión, pero en el teatro cabe perfectamente que un actor se represente a sí mismo si la acción escénica lo requiere. O que empiece haciéndolo para derivar luego al juego escénico representando otro personaje o varios personajes. Incluso en la manera de asumir esta tarea hay una infinita gama de posibilidades.

No he visto a Vargas Llosa haciendo de Odiseo, pero sí lo he visto haciendo de Sahrigar y he disfrutado de su actuación. Nunca se me hubiese ocurrido pedirle que encarnara de manera integral el papel de Sahrigar, que es 
lo que a mí me gustaría hacer, aunque no sé si sería capaz. Su propuesta es la del narrador que busca la compañía de una actriz para convocar a un público y dedicarse a mentir juntos, contando con la ayuda de un texto especialmente preparado para ese efecto y la de un equipo especializado en el arte del teatro.

Recuerdo haber bromeado con él, llamándolo "joven dramaturgo", como ahora podría hacerlo llamándolo "novel actor", aunque ya sea premio Nobel. Su desempeño en escena no solamente ha mejorado en cuanto a su capacidad de memorizar y decir el texto con sentido de escena, sino en saber qué acción se cumple en cada momento. Los viejos del teatro decían que si el actor sabía su letra y no se tropezaba con los muebles era más que suficiente. Es y no es verdad, como todo en el teatro. No lo es porque hay muchísimo más por hacer en un trabajo teatral. Pero lo es porque si hay sentido de verdad en lo que hace el actor frente al público, éste lo agradecerá con su atención y el aplauso.

En conclusión, no puedo dejar de dar testimonio no solamente del real interés que siempre ha tenido Mario Vargas Llosa por el teatro, sino también de su incuestionable compromiso con quienes lo hacen. A su condición de permanente espectador de teatro en el lugar donde se encuentre y la de tener presente en la imaginación a los personajes que puedan producir situaciones concretas en un escenario que convoquen la atención de un público se ha sumado la vocación misma del actor, que es la más importante en el teatro, al margen del incuestionable valor que tienen todas las funciones posibles en la creación escénica. Por eso lo hemos visto en escena y algunos pocos hemos tenido la ocasión de verlo asistir a los ensayos de una de sus obras durante toda la temporada, gozando y sufriendo el proceso de la puesta en escena sin intervenir directamente en el proceso mismo, pero atendiendo el pedido de los actores y el director sobre aquellos aspectos que pudiesen ser revisados, corregidos, mejorados en función del resultado que se venía obteniendo.

Hay un refrán que se repite en el teatro por algunos directores: "el mejor autor es el autor muerto". Esto se debe obviamente a que los autores han imaginado de alguna manera su obra y quieren, y a veces exigen —en ocasiones sin mayor fundamento artístico - al productor, al director e incluso a los actores que ella se haga de acuerdo a como él la imaginó. Nada más lejano de la actitud de Vargas Llosa, quien escribe lo que él quiere pero deja absoluta libertad —en ocasiones excesiva libertad, según algunos - a quienes se ocupan del montaje de su obra. El respeto a los actores, al director y a los equipos de teatro es absolutamente incuestionable en Vargas Llosa, que tiene por el teatro lo más cercano a lo que puede llamarse amor. 
El tiempo de Vargas Llosa en el teatro me recuerda el proceso que de manera muy sencilla describía el viejo Pirandello; esto es, que la creación dramática no es solamente lo que pueda escribir un escritor, concebir un director o encarnar un actor, sino una acción vital hecha para un espectador y que se mantiene momento a momento gracias a un viejo invento indestructible del ser humano que conocemos de manera general con el nombre de teatro.

\section{Pontificia Universidad Católica del Perú}

\section{Notas}

Ponencia presentada por Mario Vargas Llosa en el simposio "El Universo del escritor: la ciudad, la conversación y el mundo". Universidad de Murcia, 24-28 de octubre de 2011.

2 Odiseo y Penélope se presentó en el Teatro Romea de Barcelona en octubre del 2005 con la dirección de Joan Ollé.

\section{Obras citadas}

Cueto, Alonso. Mario Vargas Llosa. La vida en movimiento. Lima: Fondo Editorial UPC, 2003. Impreso.

Vargas Llosa, Mario. Al pie del Támesis. Lima: Alfaguara, 2008. Impreso. . La Chunga. Barcelona: Seix Barral, 1983. Impreso. . Las mil noches y una noche. Madrid: Alfaguara, 2008. Impreso. . Obra reunida. Teatro. Madrid: Alfaguara, 2001. Impreso. . Odiseo y Penélope. Barcelona: Galaxia Gutenberg, 2007. Impreso. . Ojos bonitos, cuadros feos. Lima: PEISA, 1996. Impreso. . La señorita de Tacna. Barcelona: Seix Barral, 1981. Impreso. 